\title{
CALAGEM E ADUBAÇÃO MINERAL E ORGÂNICA DO CAFEEIRO NA REGIÃO DE CAMPINAS $\left({ }^{1}\right)$
}

\author{
GENÉSIO DA SILVA CERVELLINI $\left({ }^{2,4}\right)$, TOSHIO IGUE $\left(^{3}\right)$ e SÉRGIO VASCO DE TOLEDO $\left(^{2}\right)$
}

\begin{abstract}
RESUMO
Instalou-se um experimento com cafeeiro cultivar Mundo Novo LCP 387-17 em um latossolo roxo transição para latossolo vermelho-amarelo orto, cuja vegetaçāo original era típica de cerrado, na região de Campinas, comparando-se os tratamentos com esterco de curral e adubação mineral NPK, complementados ou não com calcário dolomítico e com os micronutrientes zinco e boro. Aplicaram-se, por ano e por cova, 40 litros de esterco quando na ausência de NPK e 20 litros quando com NPK. A adubação mineral constou da utilização de $120 \mathrm{~g}$ de $\mathrm{N}, 40 \mathrm{~g}$ de $\mathrm{P}_{2} \mathrm{O}_{5}$ e $120 \mathrm{~g}$ de $\mathrm{K}_{2} \mathrm{O}$ por ano e por cova; quando em presença de esterco, usou-se metade dessas doses. O calcário foi aplicado na quantidade de $1 \mathrm{~kg}$ por ano e por cova, e zinco e boro, na quantidade de $20 \mathrm{~g}$ de sulfato de zinco e $20 \mathrm{~g}$ de bórax, também por cova e por ano. A análise das produçōes de café beneficiado no período de 1965 a 1970 permitiu constatar que a testemunha e o tratamento com NPK foram significativamente inferiores aos demais. Destacaram-se com as melhores produções os tratamentos que receberam esterco mais NPK, com ou sem calcário. Nas análises de solos, constatou-se aumento nas bases quando foi aplicado o esterco e, em contrapartida, aumento de acidez com o tratamento de NPK. As análises das folhas mostraram efeitos sobre teores de alumínio e manganês coerentes com os dados obtidos nas produções e análises do solo.
\end{abstract}

Termos de indexação: cafeeiro, calagem, adubação mineral c orgânica.

\section{ABSTRACT \\ LIMING AND MINERAL AND ORGANIC FERTILIZATION OF COFFEE TREE AT CAMPINAS REGION, STATE OF SÃO PAULO, BRAZIL}

Experiments with mineral and organic manure were carried out in a Red Latosolic Soil Transition to Orto Red Yellow Latosolic Soil at Campinas region with Mundo Novo LCP 387-17 coffee tree cultivar. The treatments with manure was compared with the treatments with mineral fertilizers of NPK with or without lime or micronutrients zinc and boron. The analyses of coffee production data showed that the treatments

(1) Trabalho recebido para publicação em 1. de novembro de 1973 e aceito em 7 de novembro de 1994.

$\left(^{2}\right)$ Seção de Café, Instituto Agronômico de Campinas (IAC), C: a Postal 28, 13001-970 Campinas (SP).

$\left({ }^{3}\right)$ Seção de Técnica Experimental e Cálculo, IAC.

(4) Com bolsa de pesquisa do CNPq. 
with mineral fertilizers and the test treatment with no fertilizer, had the lowest productions. The treatments with manure and NPK with or without lime had better production than other treatments. The soil analyses showed high levels of bases on the manure treatments and high acidity on the NPK treatments. The leaf analyses confirmed the results of the effects of the treatments on the aluminium and manganese contents.

Index terms: coffee tree, liming, mineral organic and fertilization.

\section{INTRODUÇÃO}

Até o início dos anos cinqüentas, a cafeicultura era instalada nos solos mais férteis, com muita matéria orgânica, e mantidos com adubações anuais de esterco de curral e pequenas quantidades de fertilizantes minerais, como salitre-do-chile e cloreto de potássio (Amaral, 1925). Em 1951, a Seção de Café do IAC passou a recomendar quantidades bem maiores de fertilizantes minerais em aplicações fracionadas durante o período chuvoso e dispensando a idéia da essencialidade da adubação orgânica (Lazzarini et al., 1967). O experimento de adubação do cafeeiro plantado em solo sob vegetação de cerrado, na região de Batatais (Lazzarini et al., 1975), contendo tratamentos com esterco, NPK, calcário e $\mathrm{Zn}$ e $\mathrm{B}$, mostrou que os tratamentos com esses produtos minerais na ausência de esterco, produziram tão bem quanto os tratamentos com esterco complementados com os mesmos produtos químicos. Mostrou, também, que a correção do solo pela calagem foi importante para o aumento da produção e para a recuperação de solos como os de cerrados, de acordo com os trabalhos de Lazzarini et al. (1967, 1975), confirmado pelas análises químicas do solo (Cervellini, 1976).

Esses conhecimentos foram divulgados na época mediante palestras e inúmeras excursões ao local do ensaio, pois era a solução para uso dos solos sob vegetação de cerrado, até então não cultivados. Tal ensaio foi o plantio pioneiro em solos sob vegetação de cerrado, sendo modelo para os plantios em Garça e Marília e, posteriormente, em outros Estados (Gonçalves, 1975).

Entretanto, encontram-se nos pareceres emitidos desde 1950 (não publicados) recomendações de aplicação de calcário em solos com forte acidez, isto é, com pH (em água) abaixo de 4,5. Inicial- mente, na quantidade de 500 g por cova e, já em 1951 , de 2.000 a $3.000 \mathrm{~kg}$ por hectare.

Pavan \& Igue (1976), estudando a aplicação de doses crescentes de calcário em cafeeiros com dez anos de plantio, verificaram que houve movimentação do $\mathrm{Ca}$ e do $\mathrm{Mg}$ até a profundidade de 60 e $100 \mathrm{~cm}$ respectivamente, e que ocorreu a neutralização do alumínio nocivo. Também houve aumentos na produção com a aplicação de calcário, sendo a maior para a dose de 2,5 t/ha. Garcia et al. (1980) estudaram também a aplicação de calcário em doses crescentes até 32 t/ha: verificaram que a segunda produção do cafeeiro foi crescente até $4 \mathrm{t} / \mathrm{ha}$, atingindo $2.136 \mathrm{~kg} / \mathrm{ha}$ de café beneficiado. Esse resultado persistiu nas duas outras colheitas, atingindo 2.136 e $1.662 \mathrm{~kg} / \mathrm{ha}$ de café beneficiado (Garcia, 1983).

O objetivo deste trabalho foi verificar o efeito da aplicação de fertilizantes minerais (NPK) com esterco, calcário, B e Zn, na produção do cafeeiro Mundo Novo LCP 387-17.

\section{MATERIAL E MÉTODOS}

Foi plantado, em 1960, em um latossolo roxo transição para latossolo vermelho-amarelo orto, série Venda Grande, cuja vegetação era típica de cerrado, do Centro Experimental de Campinas (IAC), o cultivar Mundo Novo LCP 387-17, em canteiros de quatro linhas com quatro covas e quatro plantas, no espaçamento de $3 \times 2 \mathrm{~m}$, considerando-se como úteis as quatro covas centrais.

O delineamento foi de blocos ao acaso, com seis repetições e oito tratamentos: 1 . testemunhas: sem adubo algum; 2. esterco; 3. esterco mais NPK; 4. esterco mais NPK e calcário; 5. NPK; 6. NPK mais calcário; 7. NPK mais Zn e B; 8 . NPK mais calcário mais $\mathrm{Zn}$ e $\mathrm{B}$. 
As análises químicas do solo original, média de três amostras coletadas, apresentaram os seguintes resultados: 4,74 para $\mathrm{pH}$ em água; $19,2 \mathrm{~g} / \mathrm{kg}$ de $\mathrm{C} ; 8,5,3,0,17,0,3,2$ e $77,0 \mathrm{mmol}_{\mathcal{C}} / \mathrm{kg}$, respectivamente, de $\mathrm{P}, \mathrm{K}, \mathrm{Ca}, \mathrm{Mg}$ e $\mathrm{H}+\mathrm{Al}$. As análises físicas nas profundidades de 0-30, 30-60 e 60-90 $\mathrm{cm}$ revelaram, respcctivamente, as seguintes porcentagens de argila: 53,$2 ; 54,0$ e 54,1 ; limo: 3,5 ; 6,4 e 12,2 ; areia fina: 20,$0 ; 18,8$ e 13,0 , e areia grossa: 23,$3 ; 20,8$ e 20,7 .

As quantidades e formas de aplicação dos fertilizantes e corretivos foram determinadas de acordo com conhecimentos anteriores e se referem ao total anual aplicado por cova.

O esterco de curral, curtido e seco, foi aplicado no tratamento 2: 15 litros na cova de plantio, 10 litros no $1 .^{\circ}$ ano de campo, 20 litros no $2 .^{\circ}$ ano de campo e 40 litros a partir do $3 .^{\circ}$ ano, sempre em cobertura. Para os tratamentos 3 e 4 , aplicou-se a metade do esterco indicado para o tratamento 2.

Os tratamentos $5,6,7$ e 8 receberam os fertilizantes minerais, sem esterco. O nitrogênio foi aplicado na forma de sulfato de amônia nas quantidades de $20 \mathrm{~g}$ de $\mathrm{N}$ no $1 .^{\circ}$ ano de plantio, 40 $\mathrm{g}$ de $\mathrm{N}$ no $2 .^{\circ}, 80 \mathrm{~g}$ de $\mathrm{N}$ no $3 .^{\circ}$ e $120 \mathrm{~g}$ de $\mathrm{N}$ do $4 .^{\circ}$ ano em diante. $\mathrm{O}$ fósforo foi aplicado na cova de plantio, sob as formas de fosfato-de-olinda e superfosfato simples, $200 \mathrm{~g}$ de cada um, e 200 $g$ de fosfato-de-olinda, por ano, até o $4 .^{\circ}$ ano (1964); a seguir, aplicaram-se anualmente $200 \mathrm{~g}$ de superfosfato simples por cova. O potássio foi usado na forma de cloreto, $25 \mathrm{~g}$ na cova de plantio, $50 \mathrm{~g}$ no $2 .^{\circ}$ ano de campo, $100 \mathrm{~g}$ no $3 .^{\circ}$ e $200 \mathrm{~g}$ do $4 .^{\circ}$ ano em diante, sempre em cobertura por cova, sob as copas dos cafeeiros, em quatro parcelamentos, de outubro a abril. Do calcário dolomítico, aplicaram-se $50 \mathrm{~g}$ na cova de plantio, $100 \mathrm{~g}$ no $1 .^{\circ}$ ano de campo, $200 \mathrm{~g}$ no $2 .^{\circ}, 400 \mathrm{~g}$ no $3 .^{\circ} \mathrm{e} 4 .^{\circ}$ ano; do $5 .^{\circ}$ ano (1965) em diante, a quantidade passou a ser de $1.000 \mathrm{~g}$ por cova, em cobertura, sob as copas, em uma só vez, durante o verão, em data distante da aplicação dos fertilizantes. O $\mathrm{B}$ e o Zn foram aplicados, respectivamente, como ácido bórico a $0,2 \%$ e sulfato de zinco a $0,5 \%$ de concentração, em pulverizações em outubro, dezembro, fevereiro e abril. A partir de 1965, passaram a ser aplicados no solo nas formas de bórax e sulfato de zinco, 20 g por cova, para cada um, em cobertura, sob as copas, em uma só vez, anualmente.

\section{RESULTADOS E DISCUSSÃO}

No quadro 1, encontram-se as produções médias anuais dos tratamentos, as médias por biênio e a média do período de seis anos, expressas em quilogramas de café beneficiado por hectare. No quadro 2 , os totais de chuva no período de 1964-75, observados no Centro Experimental de Campinas.

A produção de 1965 , a primeira obtida nesses cafeeiros que não produziram em 1963 e 1964, devido à grande seca de 1963, foi considerada extraordinária. As produções de 1966, 1967 e 1968 foram razoáveis, decrescentes, provavelmente por não terem ocorrido condições para recuperação do sistema radicular. As poucas chuvas a partir da primavera de 1968 parecem ter comprometido as produçōes de 1969, que foram muito baixas. As de 1970 foram bem elevadas, por efeito da baixa produção anterior e das abundantes chuvas na primavera, demonstrando elevados efeitos da aplicação do calcário na presença dos fertilizantes minerais (NPK) e especialmente quando acompanhado de esterco. Esta alta produção provocou seca das plantas por esgotamento, necessitando recepagem.

Após a recepa de 1970 , as plantas não se recuperaram, sendo desconsideradas as produções até 1973.

Pelas médias, observa-se que os tratamentos com NPK e sem fertilizante são os únicos que diferiram dos demais pelas produções mais baixas. Estatisticamente, as outras médias não diferiram entre si, mostrando a viabilidade do cultivo de café com a utilização dos fertilizantes minerais NPK, desde que feita a correção da acidez do solo e das deficiências de micronutrientes, nesse tipo de solo estudado.

O tratamento com esterco apresentou uma média de produção $20 \%$ menor do que a obtida com esterco mais NPK, apesar de se utilizar, neste último, apenas metade do esterco aplicado no primeiro tratamento, indicando que o esterco sozinho não encerra os nutrientes em quantidade suficiente, sobretudo 


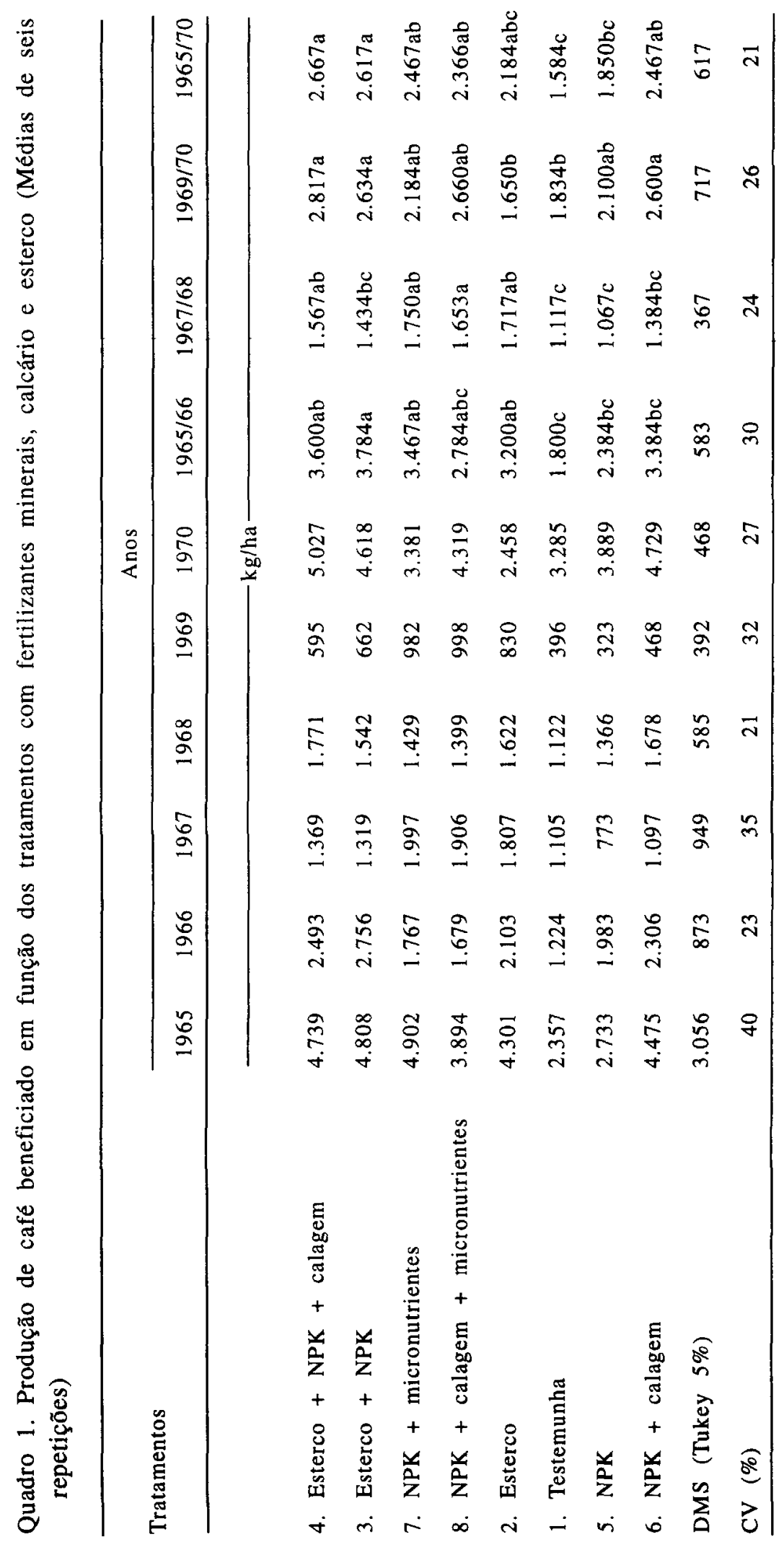




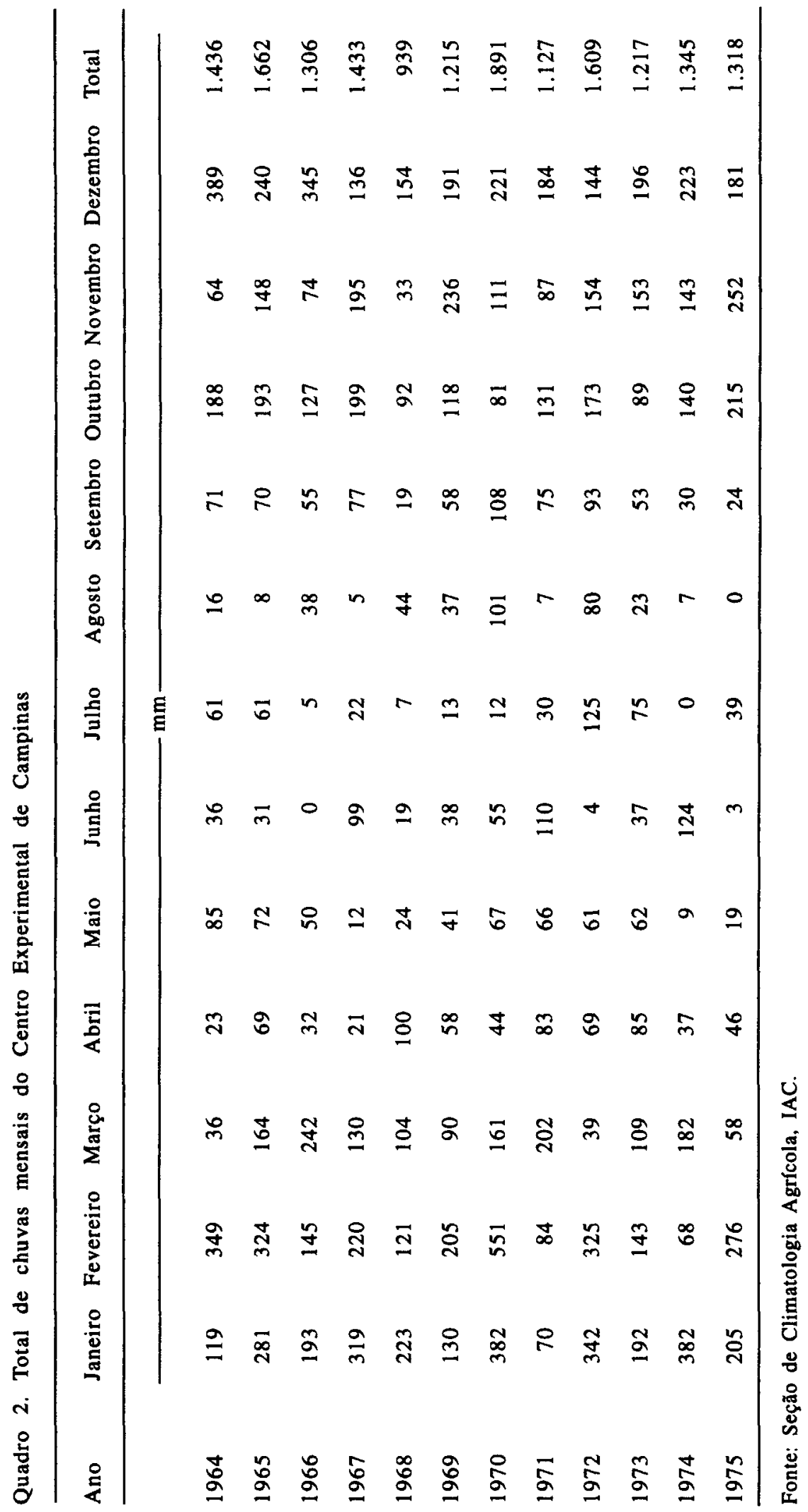


o nitrogênio (Moraes et al., 1976), pois 401 de esterco aplicado anualmente contêm apenas $60 \mathrm{~g}$ de $\mathrm{N}$, metade da aplicação anual de $\mathrm{N}$ na forma mineral.

A adição do calcário dolomítico aos fertilizantes minerais com NPK não induziu, no solo de Campinas, os mesmos efeitos na produção observados em Batatais, em experimento idêntico (Lazzarini et al., 1975). O solo de Campinas apresentava teores mais elevados de $\mathrm{K}, \mathrm{Ca}$ e $\mathrm{Mg}$. A acidez potencial $(\mathrm{Al}+\mathrm{H})$, mais elevada, indicou necessidade maior de calcário em Campinas, considerando também a acidificação provocada pelos fertilizantes (Moraes et al., 1979).

$\mathrm{A}$ aplicação do $\mathrm{B}$ e $\mathrm{Zn}$ beneficiou a produção conforme se verifica pelos contrastes dos tratamentos 7 e 8 , respectivamente, com 5 e 6 . Os micronutrientes contidos no esterco, em formas de complexos orgânicos que Stevenson \& Ardakami (1972) citam como maiores responsáveis pela disponibilidade de boro e molibdênio, provavelmente tenham favorecido a atuação deste quando completados com NPK e calcário, permitindo concluir que o solo é deficiente em $\mathrm{B}$ e $\mathrm{Zn}$.

A interação do Zn e B com o calcário é observada quando comparadas, por contraste, as produções dos tratamentos $8 \mathrm{com} \mathrm{5,6} \mathrm{e} 7$.

A análise do solo dos vários tratamentos indica que as parcelas que receberam somente fertilizantes minerais ficaram com o solo acidificado, o que pode ter prejudicado a produção (Quadro 3).

Nas parcelas onde se aplicou esterco de curral, os teores de cálcio e magnésio foram bem mais elevados, superando inclusive os índices das parcelas com calcário. O teor de alumínio livre do solo foi eliminado nos tratamentos com 401 de esterco ou 201 de esterco mais $1 \mathrm{~kg}$ de calcário por ano. A adição do $\mathrm{Zn}$ e·do $\mathrm{B}$ elevou o teor de alumínio livre, talvez por efeito da provável maior atividade biológica dos microorganismos do solo na presença dos micronutrientes apjlicados, aumentando também os teores de fósforo e potáṣsio quando sem aplicação de calcário.

A análise do efeito da aplicação do calcário fica prejudicada, pois as amostragens foram realiżadas a profundidades diferentes. Para a ausência do calcário, nota-se pH 5,3 e 4,0 mmol/kg de Al à profundidade de $0-20 \mathrm{~cm}$; na presença de calcário, à profundidade de $0-5 \mathrm{~cm}$, o pH foi 4,7 e não há alumínio livre; para profundidades maiores, foi reduzida a acidez e não se encontrou também o $\mathrm{Al}^{3+}$. Para o calcário aplicado com NPK e micronutrientes, o $\mathrm{pH}$ foi 7,1 , e os teores de $\mathrm{Ca}+\mathrm{Mg}$, mais elevados, não se encontrando Al.

O quadro 4 apresenta os resultados da análise foliar para teores de nutrientes, em função dos tratamentos com NPK, NPK + calcário e testemunha.

Os teores de NPK e de sulfato e cloreto nas folhas de café das parcelas testemunhas foram menores que os teores dos tratamentos contendo esses nutrientes.

As alterações do $\mathrm{pH}$ juntamente com as adições de radicais negativos, como os carbonatos, o nitrato, o sulfato e outros, modificam a atividade dos metais (Lindsay, 1972). Isso pode ser observado nos teores de alumínio em amostras realizadas por Moraes et al. (1979) em folhas de cafeeiros, por ocasião do segundo corte, em relação aos fertilizantes e corretivos e à acidez do 1atossolo roxo para cada tratamento, com uréia mais carbonato de cálcio e uréia mais enxofre com $\mathrm{pH} 8,0$ e 3,8 e teor de $\mathrm{Al}^{3+} 210$ e $260 \mathrm{mg} / \mathrm{kg}$ respectivamente. Para o cálcio, não houve diferença estatística entre os teores observados e, para o magnésio, o tratamento NPK apresentou o menor teor, sendo iguais para os outros tratamentos.

Para os micronutrientes, encontraram-se os maiores teores de alumínio, zinco, ferro e cobre e os menores para boro e molibdênio nas folhas do tratamento com NPK e pH do solo 4,8, os quais não diferiram dos teores dos tratamentos com NPK mais calcário cujo pH do solo foi 7,1 . Provavelmente esses teores sejam efeitos das adições de carbonatos ou nitratos, conforme observado acima.

O teor de manganês nas folhas foi menor no tratamento com calcário e menor ou igual nos outros dois, indicando a neutralização do manganês tóxico em $\mathrm{pH}$ mais elevado que 5,1 , obtido no testemunha. 
Quadro 3. Análise química do solo dos tratamentos do ensaio de adubação orgânica e química de Campinas

\begin{tabular}{lccccccc}
\hline \multirow{2}{*}{ Tratamentos } & $\begin{array}{c}\text { Profundidade } \\
\text { de amostragem }\end{array}$ & $\begin{array}{c}\mathrm{pH} \\
\text { (água) }\end{array}$ & $\mathrm{C}$ & $\mathrm{P}$ & $\mathrm{K}$ & $\mathrm{Ca}+\mathrm{Mg}$ & $\mathrm{Al}$ \\
\hline \multirow{2}{*}{ Esterco (E) } & $\mathrm{cm}$ & & $\mathrm{g} / \mathrm{kg}$ & & & & \\
& $0-5$ & 5,60 & 25,0 & 10,0 & 7,0 & 120,0 & - \\
& $5-10$ & 5,60 & 24,0 & 5,2 & 5,0 & 110,0 & - \\
& $10-20$ & 5,70 & 24,0 & 0,4 & 4,0 & 110,0 & - \\
NPK & $0-20$ & 4,80 & 15,0 & 2,7 & 0,9 & 13,0 & 8,0 \\
NPK + micro & $0-5$ & 4,60 & 20,0 & 10,0 & 7,5 & 7,0 & 42,0 \\
& $5-10$ & 4,60 & 20,0 & 3,2 & 6,5 & 7,0 & 21,0 \\
& $10-20$ & 4,50 & 21,0 & 0,6 & 5,4 & 11,0 & 8,0 \\
E + NPK & $0-20$ & 5,30 & 20,0 & 0,4 & 4,0 & 36,0 & 4,0 \\
E + NPK + cal & $0-5$ & 4,70 & 23,0 & 0,9 & 10,0 & 38,0 & - \\
& $5-10$ & 5,10 & 26,0 & 2,4 & 7,0 & 109,0 & - \\
& $10-20$ & 5,30 & 26,0 & 0,8 & 7,0 & 118,0 & - \\
NPK + cal + micro & $0-20$ & 7,10 & 15,0 & 4,5 & 1,5 & 59,0 & - \\
Testemunha & $0-20$ & 5,10 & 14,0 & 0,4 & 0,7 & 14,0 & 7,0 \\
\hline
\end{tabular}

Quadro 4. Teores dos nutrientes em folhas de cafeeiros coletadas em 1969, do ensaio de Campinas (médias de seis repetições)

\begin{tabular}{|c|c|c|c|c|c|}
\hline Nutrientes & Test. & NPK & $\begin{array}{c}\text { NP } \\
\text { calcário }\end{array}$ & $\mathrm{F}$ & $\begin{array}{c}\text { Tukey } 1 \% \\
\text { dms }\end{array}$ \\
\hline $\mathrm{N}, \mathrm{g} / \mathrm{kg}$ & $26,6 \mathrm{~b}$ & 32,3 a & 32,0 a & $36,78 * *$ & 3,24 \\
\hline $\mathrm{P}, \mathrm{g} / \mathrm{kg}$ & 1,26 & 1,44 & 1,40 & - & - \\
\hline $\mathrm{K}, \mathrm{g} / \mathrm{kg}$ & $18,5 \mathrm{~b}$ & 28,5 a & 28,9 a & $9,54 * *$ & 8,68 \\
\hline $\mathrm{Ca}, \mathrm{g} / \mathrm{kg}$ & 9,5 & 7,8 & 8,8 & - & - \\
\hline $\mathrm{Mg}, \mathrm{g} / \mathrm{kg}$ & $4,5 \mathrm{a}$ & $3,5 \mathrm{~b}$ & 4,6 a & $10,21 * *$ & 0,81 \\
\hline $\mathrm{S}$ (sulfato), $\mathrm{g} / \mathrm{kg}$ & $0,78 \mathrm{~b}$ & $1,42 a b$ & $1,62 \mathrm{a}$ & $17,31 * *$ & 0,81 \\
\hline $\mathrm{Al}, \mathrm{mg} / \mathrm{kg}$ & $113 \mathrm{~b}$ & $167 \mathrm{ab}$ & 207 a & $5,71 * *$ & 92,6 \\
\hline $\mathrm{Mn}, \mathrm{mg} / \mathrm{kg}$ & 295,6 a & 276,6 a & $205,2 \mathrm{~b}$ & $53,79 * *$ & 31,13 \\
\hline $\mathrm{B}, \mathrm{mg} / \mathrm{kg}$ & 73,4 a & $48,6 \mathrm{~b}$ & $48,7 \mathrm{~b}$ & $26,16 * *$ & 13,0 \\
\hline $\mathrm{Zn}, \mathrm{mg} / \mathrm{kg}$ & 9,8 & 12,4 & 11,1 & - & - \\
\hline Mo, $\mathrm{mg} / \mathrm{kg}$ & 0,125 & 0,115 & 0,114 & - & - \\
\hline $\mathrm{Fe}, \mathrm{mg} / \mathrm{kg}$ & $100 \mathrm{~b}$ & $147 \mathrm{a}$ & $170 \mathrm{a}$ & $12,59 * *$ & 42,27 \\
\hline $\mathrm{Cu}, \mathrm{mg} / \mathrm{kg}$ & $14,0 \mathrm{~b}$ & 20,6 a & 19,2 a & $26,4^{* *}$ & 0,081 \\
\hline $\mathrm{Cl}$ (cloreto) $\mathrm{mg} / \mathrm{kg}$ & $0,076 \mathrm{~b}$ & $0,35 \mathrm{a}$ & 0,408 a & $49,9 * *$ & 0,101 \\
\hline
\end{tabular}

Obs: Para $\mathrm{P}, \mathrm{Ca}, \mathrm{Zn}$ e Mo não foi feita análise estatística. 


\section{CONCLUSÕES}

1. O esterco adicionado (20 1) ao fertilizante mineral (NPK) aumentou a produção de café. A aplicação do esterco somente (40 l) resultou em menor produção.

2. A calagem associada ao esterco ou ao NPK aplicado aumentou a produção.

3. A quantidade de $120 \mathrm{~g}$ de $\mathrm{N}$ aplicada anualmente por cova mostrou-se baixa, dificultando a recuperação do cafeeiro após altas produções.

\section{AGRADECIMENTOS}

Os autores agradecem a Ferdinando R. Pupo de Moraes a coordenação e condução do experimento até sua aposentadoria.

\section{REFERÊNCIAS BIBLIOGRÁFICAS}

AMARAL, A.P. do. A cultura prática e racional do cafeeiro. São Paulo, Secretaria da Agricultura, Comércio e Obras Públicas do Estado de São Paulo. 1925. 607p.

CERVEllini, G. da S. Propriedades químicas de um solo de cerrado utilizado para a cafeicultura. Piracicaba, 1976. 50p. Tese (Mestrado) - ESALQ-USP, 1976.

GARCIA, A.W.R. Calagem para o cafeeiro. In: REUNIÃO BRASILEIRA DE FERTILIDADE DO SOLO, 15., Campinas, 1982. Anais. Campinas, Sociedade Brasileira de Ciência do Solo, 1983. p.309-320.

GARCIA, A.W.R.; FIORAVANTE, N.E. \& SILVA, J.B.S. Doses crescentes de calcário na formação do cafeeiro em LVE, fase cerrado. In: CONGRESSO BRASILEIRO DE PESQUISAS CAFEEIRAS, 8., Campos de Jordão, 1980. Resumos. Rio de Janeiro, Instituto Brasileiro de Café, 1980. p.38-41.
GONÇALVES, J.C. Aproveitamento do cerrado brasileiro para o cultivo do café. In: CONGRESSO BRASILEIRO DE PESQUISAS CAFEEIRAS, 3., Curitiba, 1975. Resumos. Rio de Janeiro, Instituto Brasileiro de Café, 1975. p.7-12.

LAZZARINI, W; MORAES, F.R.P. de; CERVELLINI, G. da S.; TOLEDO, S.V. de; FIGUEIREDO, J.I. de: REIS, A.J.; CONAGIN, A. \& FRANCO. C.M. CuItivo do café em latossolo vermelho-amarelo da região de Batatais. Bragantia, Campinas, 34(14):229-239. 1975.

LAZZARINI, W.; MORAES, F.R.P.; MORAES, M.V.; TOLEDO, S.V. \& FIGUEIREDO, J.I. Experimentação cafeeira. Campinas, Instituto Agronômico, 1967. 396p.

LINDSAY, W.L. Inorganic phase equilibria of micronutrientes in soils. In: MORTVEDT, J.J.; GIORDANO, P.M. \& LINDSAY, W.L., eds. Micronutrients in agriculture. 3.ed. Madison, Soil Science Society of America, 1972. p.41-57.

MORAES, F.R.P.; GALLO, J.R.; IGUE, T. \& FIGUEIREDO, J.I. Efeito de três fertilizantes acidificantes sobre a concentração de alumínio e manganês em folhas e raízes de cafeeiros. Bragantia, Campinas, 38(2):7-17, 1979.

MORAES, F.R.P.; LAZZARINI, W.; TOLEDO, S.V. de; CERVELLINI, G. da S. \& FUJIWARA, M. Fontes e doses de nitrogênio na adubação química do cafeeiro. I. Latossolo roxo-transição para latossolo vermelho-amarelo orto. Bragantia, Campinas, 35(6):63-67, 1976.

PAVAN, M.A. \& IGUE, K. Estudos de calagem em cafeeiros. In: CONGRESSO BRASILEIRO DE PESQUISAS CAFEEIRAS, 4., Caxambu, 1976. Resumos. Rio de Janeiro, Instituto Brasileiro de Café, 1976. p.41.

STEVENSON, F.J. \& ARDAKAMI, M.S. Organic matter reactions involving micronutrients in soils. In: MORTVEDT, J.J.; GIORDANO, P.M. \& LINDSAY, W.L., eds. Micronutrients in agriculture. 3.ed. Madison, Soil Science Society of America, 1972. p.79-114. 